Case Report

\title{
A Rare and Unexpected Reason for Unilateral Epistaxis: Nasal Septal Schwannoma
}

\author{
Alper Yenigun (D), ${ }^{1}$ Yasin Kulaksiz ${ }^{1}{ }^{1}{ }^{1}$ Tugce Esen Kiran ${ }^{(D)}{ }^{2}$ Erol Senturk (D), \\ Fadlullah Aksoy $\mathbb{D}^{1},{ }^{1}$ and Orhan Ozturan $\mathbb{D}^{1}$ \\ ${ }^{1}$ Bezmialem Vakif University, Faculty of Medicine, Department of Otorhinolaryngology, Fatih, Istanbul, Turkey \\ ${ }^{2}$ Bezmialem Vakif University, Faculty of Medicine, Department of Pathology, Fatih, Istanbul, Turkey \\ Correspondence should be addressed to Alper Yenigun; alperyenigun@gmail.com
}

Received 25 February 2020; Revised 18 August 2020; Accepted 30 September 2020; Published 10 October 2020

Academic Editor: Seckin Ulualp

Copyright (C) 2020 Alper Yenigun et al. This is an open access article distributed under the Creative Commons Attribution License, which permits unrestricted use, distribution, and reproduction in any medium, provided the original work is properly cited.

\begin{abstract}
Nasal septal schwannoma is a rare tumor. It causes complaints such as nasal congestion, nosebleeds, and headaches. There are many diseases such as nasal polyps, antrochoanal polyp, chronic rhinosinusitis, concha bullosa, inverted papilloma, and retention cyst with schwannoma diagnosis. The diagnosis is made histopathologically, and the treatment is surgery. In this case report, we presented a male patient with septal schwannoma who had nasal obstruction for a year and reviewed the last 20 years of literature on nasal schwannoma.
\end{abstract}

\section{Introduction}

Schwannomas are benign tumors of the nerve sheath commonly associated with cranial nerve VIII. It is observed with a frequency of $25-45 \%$ among all head and neck tumors [1-4]. Only $4 \%$ of them are seen in the nose [1]. Nasal septum is one of the places where schwannoma is rarely seen in the nose [1-5]. In this study, we presented a case of a male with septal schwannoma who had suffered nasal congestion for a year. This study was conducted to examine the frequency of schwannomas among the causes of nasal obstruction. Therefore, we also reviewed last 20 years of literature about nasal schwannoma.

\section{Case Report}

A 28-year-old male patient was admitted to our clinic with progressive nasal congestion and recurrent epistaxis. In rigid endoscopy, there was a polypoid mass originating from the septum with smooth surface and prone to bleeding. It was causing nasal obstruction on the left side of the nose (Figure 1). In paranasal sinus computed tomography (CT), approximately $16 \times 40 \times 35 \mathrm{~mm}$-sized polypoid mass was observed on the left side, filling the nasal cavity completely
(Figure 2). No extension or bone invasion to any paranasal sinuses was present. Magnetic resonance imaging (MRI) revealed a hypointense mass and heterogeneous contrast in $\mathrm{T} 1$ and $\mathrm{T} 2$ sections (Figure 3). The surgery was planned to the patient under general anesthesia. Endoscopically mucosal incision was made proximal to where the mass attaches to the septum. The procedure was continued by subperichondrial elevation. The mass was excised en bloc with the septum mucosa (Figure 4). In the histological examination of the mass, spindle cell proliferation consisting of photocellular and hypocellular alternating areas and diffuse positivity in spindle cells with $\mathrm{S} 100$ were observed (Figures 5 and 6). Vimentin staining was positive, though neuronspecific enolase and smooth muscle actin staining were negative. According to these observations, the mass was defined as a septum-derived schwannoma. No recurrence was observed during the patient's 1-year follow-up.

\section{Discussion}

Schwannoma is a class sheath tumor often seen in the head and neck region. While approximately $25-45 \%$ of schwannomas are seen in the head and neck region [1-4], only $4 \%$ of them are seen in the nose [6]. The case of 


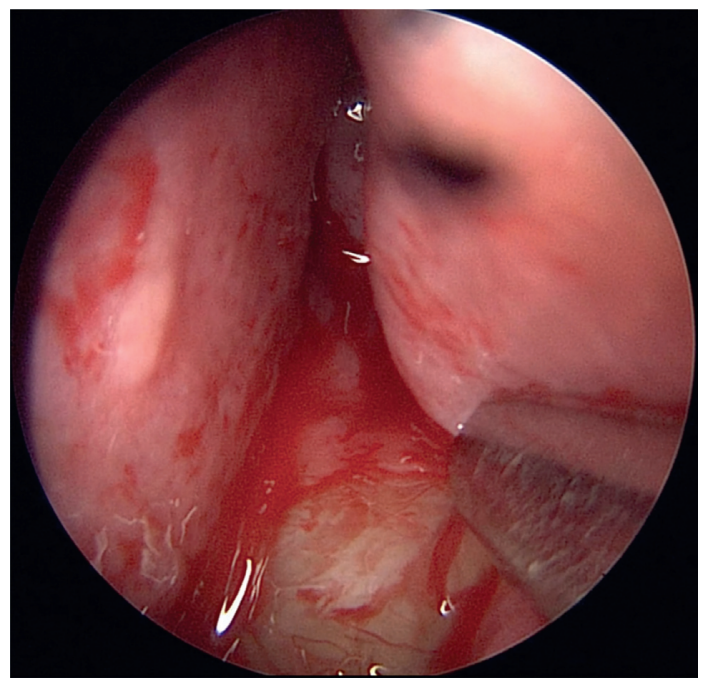

FIGURE 1: Endoscopic examination of the nose showing a large, left-sided nasal polypoid mass occluding the entire left nasal cavity.

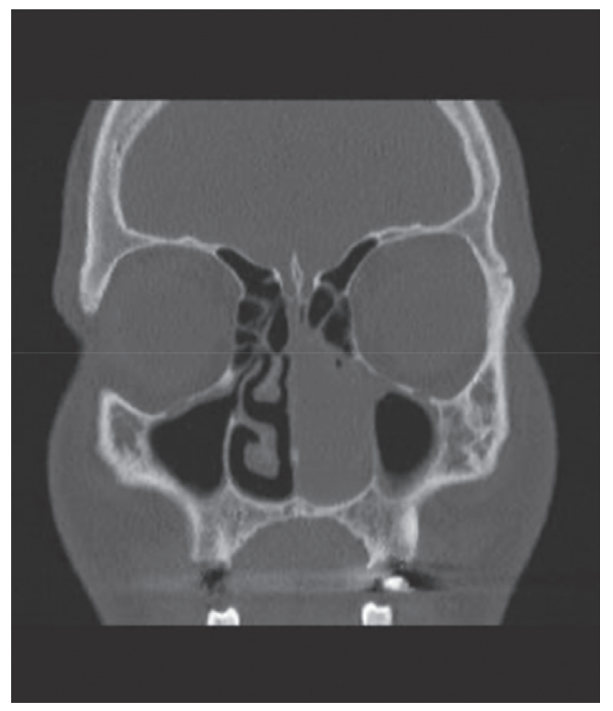

(a)

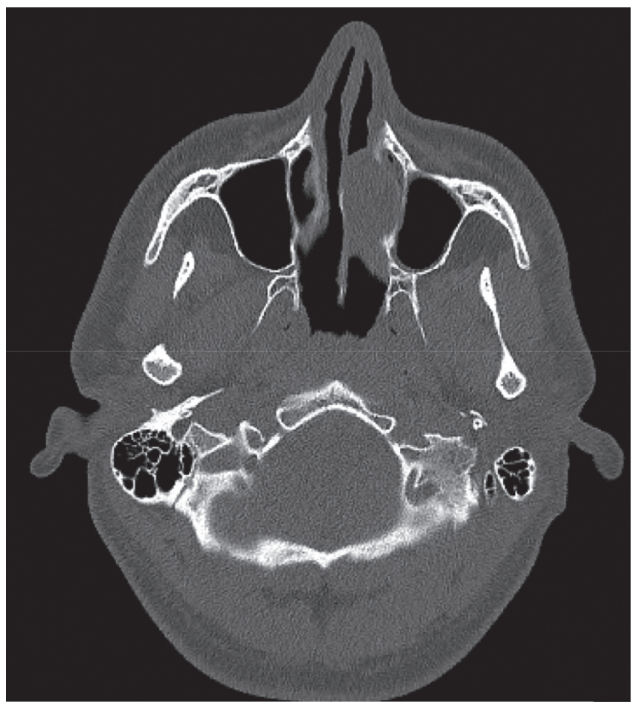

(b)

Figure 2: CT scan of the paranasal sinuses with contrast. The coronal and axial section shows a left anterior nasal mass.

schwannoma in the nasal septum was first reported by Betkowski et al. in 1943 [7]. Schwannoma is seen especially in the $4^{\text {th }}$ and $6^{\text {th }}$ decades, and there is no gender dominance [8]. Nasal septal schwannoma cases reported in the last 20 years are shown in Table 1. Schwannoma often originates from the posterior part of the septum in the nose and makes complaints such as nasal congestion, nosebleeds, and headaches [6]. In our case, it originated from the anteriormiddle region of the septum at young age different from the other cases. The unilateral mass in the nose was observed at $22 \%$ nasal polyps, $19 \%$ antrochoanal polyp, $13 \%$ chronic rhinosinusitis, $11 \%$ concha bullosa, $6 \%$ inverted papilloma, and $6 \%$ retention cyst. More rarely, fibrous dysplasia, lymphoma, pleomorphic adenoma, and schwannoma are seen. In such a large list, only observation is not sufficient for diagnosis [9]. Paranasal CT findings are nonspecific. CT often helps with the size of the tumor and where it originates. MRI tumor is better at differentiating from inflammatory diseases and normal tissue. It also shows intracranial extension [10]. In previous studies, findings such as "target sign" and "fascicular sign," which are specifically observed in schwannoma tumors on MRI, have been reported [11-14].

The definitive diagnosis of schwannoma tumor is made histopathologically. Schwannoma tumors are macroscopically seen as bordered and encapsulated. When stained with hemotoxylin-eosin stain and analyzed microscopically, it is divided into two patterns, Antoni A and Antoni B. Antoni A consists of spindle cells that form palisade by lining the nuclei side by side. Antoni B consists of loose myxoid stroma and a small amount of spindle cells. It is stained strongly with S-100 immunohistochemically $[4,15,16]$. In the histological examination of the mass of our patient, spindle cell 


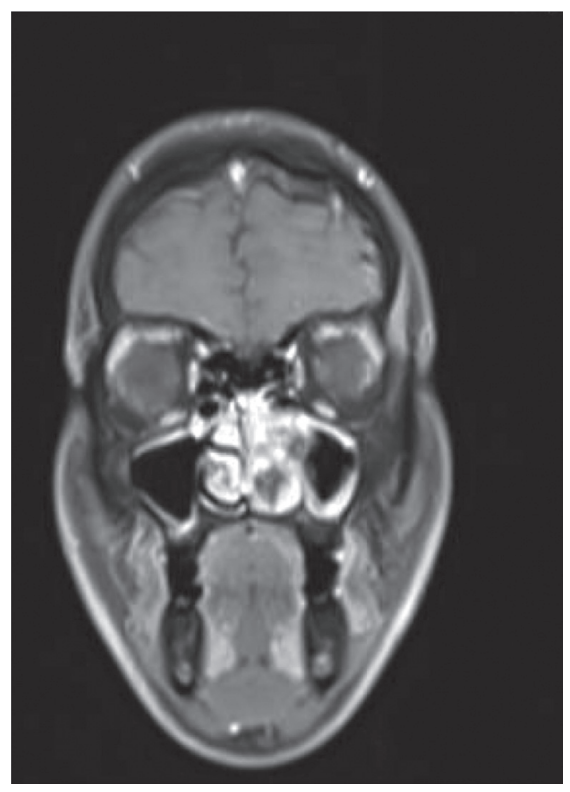

(a)

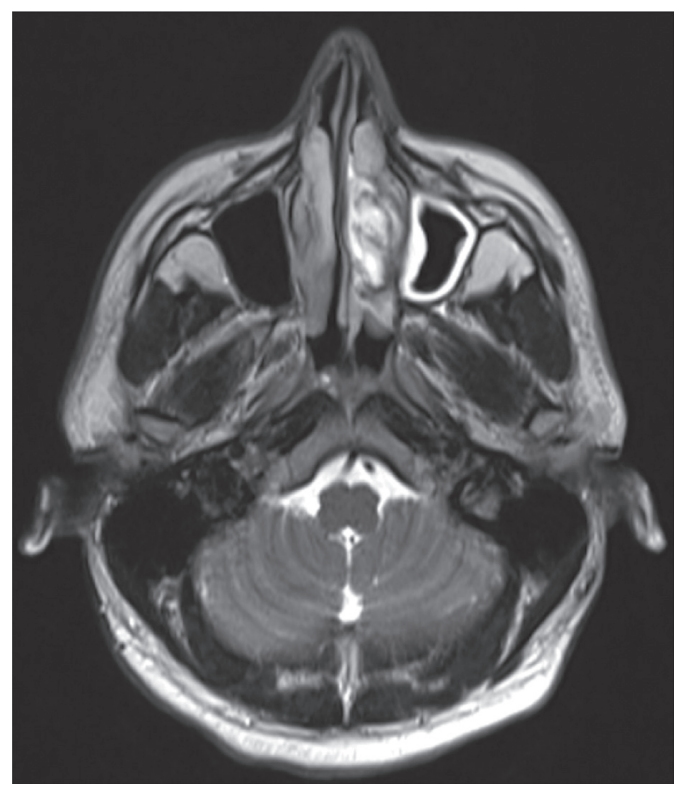

(b)

FIGURE 3: MRI scan of the paranasal sinuses with contrast. The coronal and axial section shows a left anterior heterogeneous hypointense nasal mass.

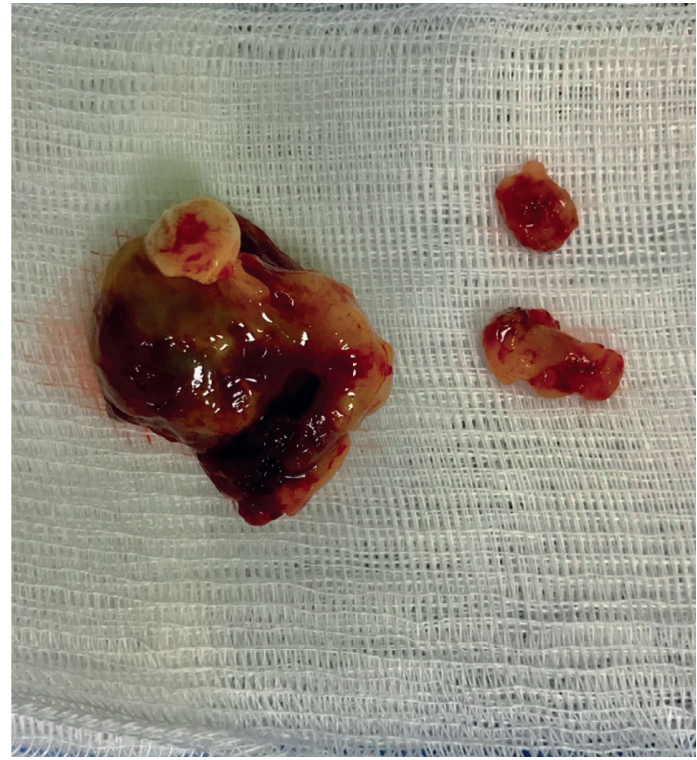

Figure 4: Gross image of the mass revealed multiple fragments of soft tan-gray tissue.

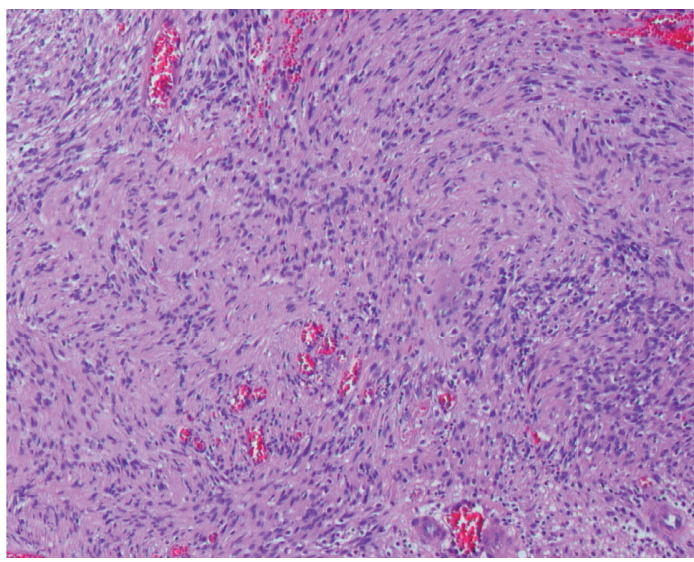

FIGURE 5: Histopathological examination showing high cellular density and a palisading pattern of the tumor cells $(\times 40$ power, H\&E-stained microscopic slide picture). 


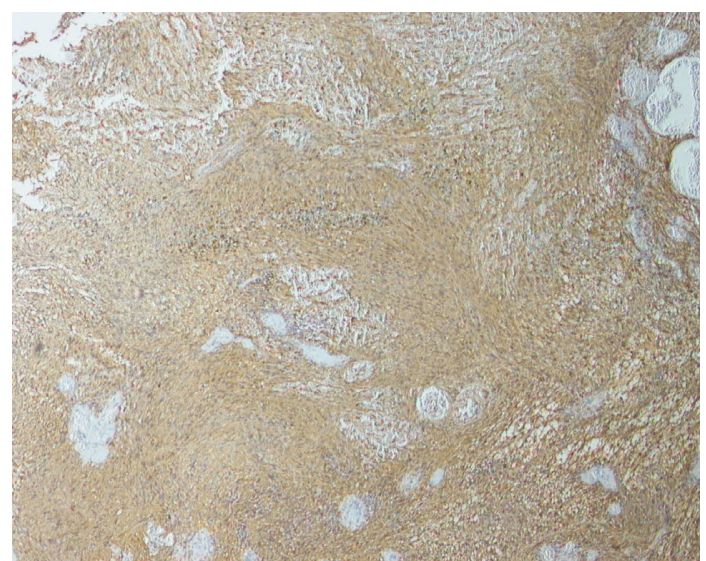

FIGURE 6: Immunohistochemistry showing tumor cells that are strongly positive for S-100.

TABLE 1: Nasal septal schwannoma cases reported in the last 20 years.

\begin{tabular}{|c|c|c|c|c|c|c|}
\hline Author(s) & Year & Age/sex & Symptoms & Site & Treatment & Follow-up \\
\hline Berlucchi et al. [4] & 2000 & $29 / \mathrm{M}$ & NO, Ep & NS & $\mathrm{Ex}$ & 7 years \\
\hline Wada et al. [18] & 2000 & $62 / \mathrm{F}$ & NO & NS & Ex & 15 months \\
\hline Wang et al. [12] & 2004 & $55 / \mathrm{M}$ & $\mathrm{NO}$ & NS & Ex & - \\
\hline Rajagopal & 2005 & $54 / \mathrm{F}$ & $\mathrm{NO}$ & NS & Ex & 6 months \\
\hline Shinohara et al. [14] & 2005 & $50 / \mathrm{M}$ & NO & NS & Ex & 3 years \\
\hline Kodama et al. [19] & 2009 & $41 / \mathrm{F}$ & $\mathrm{NO}$ & NS & Ex & 2 years \\
\hline Pauna et al. [8] & 2013 & $78 / \mathrm{M}$ & $\mathrm{NO}$ & NS & Ex & - \\
\hline Gulia et al. [20] & 2013 & $35 / \mathrm{F}$ & $\mathrm{NO}$ & Membranous NS & Ex & 6 months \\
\hline Cadd et al. [21] & 2014 & $31 / \mathrm{M}$ & NO, Ep & NS & Ex & - \\
\hline Dhingra et al. [22] & 2014 & $28 / \mathrm{F}$ & NO, Ep & NS & Ex & - \\
\hline Karatas [23] & 2016 & $31 / \mathrm{F}$ & NO, Ep & NS & Ex & 8 months \\
\hline Gerritsen et al. [24] & 2017 & $16 / \mathrm{M}$ & $\mathrm{NO}$ & NS & Ex & 1 month \\
\hline Gupta et al. [25] & 2017 & $40 / \mathrm{F}$ & NO, Ep & NS & Ex & 1 year \\
\hline Valsamidis et al. [26] & 2017 & $54 / \mathrm{M}$ & NO, Ep & NS & Ex & 6 months \\
\hline Min et al. [3] & 2017 & $65 / F$ & NO & NS & Ex & 2 years \\
\hline Devaraja et al. [27] & 2018 & $57 / \mathrm{M}$ & $\mathrm{NO}$ & NS & Ex & - \\
\hline Alrasheed et al. [28] & 2019 & $64 / \mathrm{F}$ & NO, Ep & NS & Ex & 3 years \\
\hline Bie et al. [29] & 2019 & $47 / \mathrm{M}$ & NO, Ep & NS & Ex & 6 months \\
\hline Our case & 2020 & $28 / \mathrm{M}$ & NO, Ep & NS & Ex & 1 year \\
\hline
\end{tabular}

M: male; F: female; NO: nasal obstruction; Ep: epistaxis; NS: nasal septum; Ex: excision.

proliferation consisting of photocellular and hypocellular alternating areas with S-100 and diffuse positivity in spindle cells were observed. Although neuron-specific enolase and smooth muscle actin staining were negative, vimentin staining was positive. Based on these observations, the mass was defined as septum-derived schwannoma. Treatment of nasal septal schwannoma is extensive surgical excision with a negative surgical margin. No recurrence cases were reported in literature after excision [17-29].

\section{Conflicts of Interest}

The authors declare that there are no conflicts of interest regarding the publication of this paper.

\section{References}

[1] J. D. Suh, V. R. Ramakrishnan, P. J. Zhang et al., "Diagnosis and endoscopic management of sinonasal schwannomas," ORL, vol. 73, no. 6, pp. 308-312, 2011.
[2] O. Cakmak, H. Yavuz, and T. Yucel, "Nasal and paranasal sinus schwannomas," European Archives of Oto-Rhino-Laryngology, vol. 260, no. 4, pp. 195-197, 2003.

[3] H. J. Min, S. C. Hong, and K. S. Kim, "Nasal septal schwannoma," Journal of Craniofacial Surgery, vol. 28, no. 1, pp. e97-e101, 2017.

[4] M. Berlucchi, C. Piazza, L. Blanzuoli, G. Battaglia, and P. Nicolai, "Schwannoma of the nasal septum: a case report with review of the literature," European Archives of OtoRhino-Laryngology, vol. 257, no. 7, pp. 402-405, 2000.

[5] N. Ata, E. Koç, Y. Can, and H. Balta, "Schwannoma originating from the nasal septum," Journal of Craniofacial Surgery, vol. 27, no. 2, pp. e210-e211, 2016.

[6] K. H. Mey, C. Buchwald, S. Daugaard, and J. U. Prause, "Sinonasal schwannoma-a clinicopathological analysis of five rare cases," Rhinology, vol. 44, no. 1, pp. 46-52, 2006.

[7] A. Betkowski, S. Wysocka-Kuźniar, and T. Wewiórska, "Nerwiaki przegrody nosa neurilemmoma of the nasal septum," Otolaryngologia Polska, vol. 33, no. 3, pp. 317-322, 1979. 
[8] H. F. Pauna, G. M. De Carvalho, A. C. Guimarães, R. C. K. Maunsell, and E. Sakano, "Schwannoma of the nasal septum: evaluation of unilateral nasal mass," Brazilian Journal of Otorhinolaryngology, vol. 79, no. 3, p. 403, 2013.

[9] T. E. Habesoglu, M. Habesoglu, M. Surmeli, T. Uresin, and E. Egeli, "Unilateral sinonasal symptoms," Journal of Craniofacial Surgery, vol. 21, no. 6, pp. 2019-2022, 2010.

[10] F. Fujiyoshi, Y. Kajiya, and M. Nakajo, "CT and MR imaging of nasoethmoid schwannoma with intracranial extension," American Journal of Roentgenology, vol. 169, no. 6, pp. 1754-1755, 1997.

[11] M. P. Valencia and M. Castillo, "Congenital and acquired lesions of the nasal septum: a practical guide for differential diagnosis," Radiographics, vol. 28, no. 1, pp. 205-223, 2008.

[12] L.-F. Wang, C.-F. Tai, K.-Y. Ho, W.-R. Kuo, and C.-Y. Chai, "Schwannoma of the nasal septum: a case report," The Kaohsiung Journal of Medical Sciences, vol. 20, no. 3, pp. 142-145, 2004.

[13] F. Pagella, G. Giourgos, E. Matti, and A. Colombo, "An asymptomatic schwannoma of the nasal septum: report of a unique case," Ear, Nose \& Throat Journal, vol. 88, no. 12, pp. 1264-1265, 2009.

[14] K. Shinohara, K. Hashimoto, M. Yamashita, and K. Omori, "Schwannoma of the nasal septum removed with endoscopic surgery," Otolaryngology-Head and Neck Surgery, vol. 132, no. 6, pp. 963-964, 2005.

[15] M. J. Donnelly, M. H. al-Sader, and A. W. Blayney, "Benign nasal schwannoma," The Journal of Laryngology \& Otology, vol. 106, no. 11, pp. 1011-1015, 1992.

[16] S. W. Fine, S. A. McClain, and M. Li, "Immunohistochemical staining for calretinin is useful for differentiating schwannomas from neurofibromas," American Journal of Clinical Pathology, vol. 122, no. 4, pp. 552-559, 2004.

[17] P. S. Batra, A. Luong, S. J. Kanowitz et al., "Outcomes of minimally invasive endoscopic resection of anterior skull base neoplasms," The Laryngoscope, vol. 120, no. 1, pp. 9-16, 2010.

[18] A. Wada, H. Matsuda, K. Matsuoka, T. Kawano, S. Furukawa, and M. Tsukuda, "A case of schwannoma on the nasal septum," Auris Nasus Larynx, vol. 28, no. 2, pp. 173-175, 2001.

[19] S. Kodama, T. Okamoto, and M. Suzuki, "Ancient schwannoma of the nasal septum associated with sphenoid sinus mucocele," Auris Nasus Larynx, vol. 37, no. 4, pp. 522-525, 2010.

[20] J. S. Gulia, S. S. Yadav, S. K. Basur, and A. Hooda, "Schwannoma of the membranous nasal septum," Brazilian Journal of Otorhinolaryngology, vol. 79, no. 6, p. 789, 2013.

[21] B. Cadd, C. Offiah, and G. Alusi, "A surprising cause of unilateral nasal obstruction and epistaxis: nasal septal schwannoma," Journal of Surgical Case Reports, vol. 2014, no. 3, 2014.

[22] S. Dhingra, J. Bakshi, and S. Mohindra, "Schwannoma of the nasal septum: an unusual finding," Ear, Nose, Eamp; Throat Journal, vol. 93, no. 3, pp. E4-E6, 2014.

[23] A. Karatas, I. T. Cebi, M. Salviz, A. Kocak, and T. Selcuk, "Schwannoma of the nasal septum," Egyptian Journal of Ear, Nose, Throat and Allied Sciences, vol. 17, no. 3, pp. 185-188, 2016.

[24] R. Gerritsen, D. Corao, and U. K. Shah, "Schwannoma of the nasal septum: rare presentation and literature review," International Journal of Pediatric Otorhinolaryngology Extra, vol. 17, pp. 23-26, 2017.

[25] M. Gupta, N. Rao, C. Kour, and I. Kaur, "Septal schwannoma of the nose: a rare case," Turk Otolarengoloji Arsivi, vol. 55, no. 1, pp. 41-43, 2017.
[26] K. Valsamidis, I. Koutsampasopoulou, and K. Titelis, "Nasal septal schwannoma: an extremely rare tumor," Acta Otorrinolaringologica, vol. 68, no. 2, pp. 127-128, 2017.

[27] K. Devaraja, D. R. Nayak, B. Ramaswamy, and P. Rao, "Nasal septal schwannoma: a rare sinonasal tumour with certain peculiarities," BMJ Case Reports, vol. 2018, 2018.

[28] W. Alrasheed, A. Almomen, and A. Alkhatib, "A rare case of nasal septal schwannoma: case report and literature review," International Journal of Surgery Case Reports, vol. 55, pp. 149-151, 2019.

[29] X. Bie, J. Wang, X. Sun, K. Sun, and Y. Tang, "Combined application of endoscope and low-temperature plasma knife in the excision of nasal septal schwannoma," Ear, Nose \& Throat Journal, vol. 99, no. 2, pp. 111-113, 2020. 